\title{
The Berlin Treatment Algorithm: recommendations for tailored innovative therapeutic strategies for multiple sclerosis- related fatigue
}

\author{
Christian Veauthier ${ }^{1,2^{*}}$ (D) Helge Hasselmann ${ }^{2,3}$, Stefan M. Gold ${ }^{3,4}$ and Friedemann Paul ${ }^{2,5,6}$
}

\begin{abstract}
More than $80 \%$ of multiple sclerosis (MS) patients suffer from fatigue. Despite this, there are few therapeutic options and evidence-based pharmacological treatments are lacking. The associated societal burden is substantial (MS fatigue is a major reason for part-time employment or early retirement), and at least one out of four MS patients view fatigue as the most burdensome symptom of their disease. The mechanisms underlying MS-related fatigue are poorly understood, and objective criteria for distinguishing and evaluating levels of fatigue and tiredness have not yet been developed. A further complication is that both symptoms may also be unspecific indicators of many other diseases (including depression, sleep disorders, anemia, renal failure, liver diseases, chronic obstructive pulmonary disease, drug side effects, recent MS relapses, infections, nocturia, cancer, thyroid hypofunction, lack of physical exercise). This paper reviews current treatment options of MS-related fatigue in order to establish an individualized therapeutic strategy that factors in existing comorbid disorders. To ensure that such a strategy can also be easily and widely implemented, a comprehensive approach is needed, which ideally takes into account all other possible causes and which is moreover cost efficient. Using a diagnostic interview, depressive disorders, sleep disorders and side effects of the medication should be identified and addressed. All MS patients suffering from fatigue should fill out the Modified Fatigue Impact Scale, Epworth Sleepiness Scale, the Beck Depression Inventory (or a similar depression scale), and the Pittsburgh Sleep Quality Index (or the Insomnia Severity Index). In some patients, polygraphic or polysomnographic investigations should be performed. The treatment of underlying sleep disorders, drug therapy with alfacalcidol or fampridine, exercise therapy, and cognitive behavioral therapy-based interventions may be effective against MS-related fatigue. The objectives of this article are to identify the reasons for fatigue in patients suffering from multiple sclerosis and to introduce individually tailored treatment approaches. Moreover, this paper focuses on current knowledge about MS-related fatigue in relation to brain atrophy and lesions, cognition, disease course, and other findings in an attempt to identify future research directions.
\end{abstract}

Keywords: Polysomnography, Restless legs syndrome, Personalized medicine, Resistance training, Cognitive behavioral therapy, Obstructive sleep apnea, Patient stratification, Depression, Tiredness, Fatigue, Multiple sclerosis

\footnotetext{
* Correspondence: Christian.veauthier@charite.de

${ }^{1}$ Interdisciplinary Center for Sleep Medicine, Charité - Universitätsmedizin

Berlin, Charitéplatz 1, 10117 Berlin, Germany

${ }^{2}$ NeuroCure Clinical Research Center, Charité - Universitätsmedizin Berlin,

Charitéplatz 1, 10117 Berlin, Germany

Full list of author information is available at the end of the article
} 


\section{Background}

Multiple sclerosis (MS) is a chronic inflammatory and neurodegenerative autoimmune disease of the central nervous system with multifactorial etiopathogenesis, which predominantly affects young adults and women [1-3]. At least one out of four MS patients views fatigue as the most burdensome symptom of their illness, and the majority of MS patients (more than 80\%) suffer from fatigue [4]. Fatigue may occur at any stage of the disease and can even precede MS onset by several years [5]. Fatigue is a major reason for early retirement, reduced employment, and poor quality of life in people with MS [6-8].

The 1998 clinical practice guidelines recommended by the Consortium of Multiple Sclerosis Centers (the socalled MS Council, a consensus group of 22 North American associations including the American Academy of Neurology, the Consortium of Multiple Sclerosis Centers, and the US National Multiple Sclerosis Society) have defined MS-related fatigue as "a subjective lack of physical and/or mental energy that is perceived by the individual or caregiver to interfere with usual and desired activities" [9]. According to this definition, fatigue not only is a symptom but also has a major impact on daily activities.

The precise mechanisms of MS-related fatigue are not known, and several non-MS-related possible reasons for fatigue and tiredness should be taken into account [2]. This paper reviews current data about MS-related fatigue and neuroanatomical findings, cognitive impairment, depression, disease-modifying therapies, and disease course, on the one hand, and major confounders and other (symptomatic) reasons for fatigue and tiredness, on the other. Furthermore, the aim of this paper is to provide physicians with a clinically applicable treatment algorithm for MS-related fatigue. This review is an updated and extended version of a recently published article in German [10].

\section{Assessment and diagnostics Fatigue questionnaires}

Several scales are available for measuring fatigue. The first published fatigue scale was the unidimensional Fatigue Severity Scale (FSS) in 1989 identifying the existence and severity of fatigue [11]. Nine years later, the MS Council recommended the multidimensional Modified Fatigue Impact Scale (MFIS, 21 items), measuring the impact of fatigue on cognitive functioning and psychosocial as well as physical domains [9]. The MFIS is an abbreviated version of the Fatigue Impact Scale (FIS, 40 items) [12]. The FIS itself is a more concise version of the 138 items listed by the "Multiple Sclerosis Quality-of-Life Inventory" (MSQLI) [13]. The FSS and the MFIS are not specific for MS-related fatigue and show an overlap with depression and tiredness due to sleep disorders $[2,11,14]$. Most studies used a MFIS cutoff of 38 or 45 [15-17]. For details about the psychometric data and validation of these questionnaires, please see a recent review [2]. Finally, in 2009, the Fatigue Scale for Motor and Cognitive Functions (FSMC) was introduced [18].

\section{MS fatigue and tiredness}

Unlike sleepiness, mental (cognitive) fatigue and tiredness cannot be measured by polysomnography or electroencephalography. Both can only be assessed indirectly by neuropsychological investigations or vigorimeter testing and handgrip performance [19].

Moreover, outside the specific context of MS, patients suffering from sleep disorders who were consecutively admitted to a sleep laboratory also showed high mean MFIS values (untreated sleep apnea 32.5 , periodic limb movement disorder and restless legs syndrome 44.1, insomnia 33.5) [14]. The same was found for the FSS. Compared with men and older patients, the MFIS and FSS values were higher in women and in young patients. This is of particular importance because young women are typically overrepresented among MS patients.

In summary, no objective diagnostic criteria for distinguishing between MS- and non-MS-related tiredness and fatigue exist. For this reason, other possible underlying causes of these symptoms have to be taken into account.

\section{MS-related fatigue versus sleepiness}

MS-related fatigue and tiredness can clinically and objectively (by polysomnography and by the multiple sleep latency test) be distinguished from sleepiness: Sleepiness is defined by the propensity to fall asleep, often associated with an effort to avoid sleeping and is generally caused by sleep disorders or by disturbances of the circadian rhythm [20, 21]. Therefore, screening for sleepiness is very important in fatigued MS patients because sleepiness is an important indicator for an underlying sleep disorder [22, 23]. All fatigued patients should be asked about sleepiness and fill in the Epworth Sleepiness Scale (ESS). ESS values equal or greater than 10 indicate excessive daytime sleepiness (EDS), and in this case, patients should undergo polygraphy or polysomnography [20].

However, in sleep disorders outside the context of MS (in patients suffering from sleep disorders in the general population who are admitted to a sleep laboratory), fatigue and sleepiness can occur independently or simultaneously [24, 25]. The majority of them, almost two thirds, report pathological fatigue without sleepiness and almost one fifth fatigue and sleepiness. However, only a small number of patients with sleep disorders (4\%) suffer from sleepiness and do not feel 
fatigued (13\% experienced neither fatigue nor sleepiness) [25]. This means that it is very important to ask MS patients about sleepiness, because sleepiness indicates sleep problems and is an argument against MS-related fatigue. However, these data show clearly that the lack of sleepiness is not an argument against the presence of sleep disorders: although sleepiness is more specific to an underlying sleep disorder, fatigue remains the most common symptom of an underlying sleep disorder.

\section{Fatigability and motor fatigue}

We have to distinguish between sustained perceived fatigue from load-dependent fatigability, on the one hand, and impaired performance during a motor task and an increased subjective experience of fatigue, on the other [26]. Studies investigating load-dependent abnormal fatigability, maximal strength, subjective fatigue, and surface electromyography have shown a correlation between the changes in subjective fatigue and changes in strength in people with MS-but not a relationship between subjective fatigue and the changes in the amplitude of the electromyography. In other words, repetitive motor tasks did not lead to a performance decline, but fatigue feelings clearly increased during a repetitive motor task [27]. The increased experience of fatigue can be confounded by depression, and the objective signs of fatigability are normally not assessed in clinical praxis $[19,26,28,29]$. Moreover, most published studies investigating MS-related fatigue assessed fatigue by questionnaires, as opposed to objective investigations.

As mentioned above, the MFIS can be divided into three subscales. The nine items of the "physical subscale" measure motor fatigue. Patients can perceive physical (motor) fatigue and mental (cognitive) fatigue simultaneously. An exact definition of motor fatigue is lacking, but usually, motor fatigue is defined as a reduction in maximal walking distance that cannot be explained by the degree of paresis, ataxia, or spasticity [30].

Gait recording using a camera system and infrared markers attached to the patient's body and connected by cable to a unit worn on a belt allows the objective assessment of gait abnormalities after physical exertion and exhaustion. Therefore, the changes in gait parameters after physical exertion can be regarded as one possibility to distinguish objectively motor fatigue from fatigue by depression or normal tiredness-a clear diagnostic statement which, unfortunately, is lacking in the domain of cognitive fatigue and tiredness [30].

Studies using functional magnetic resonance imaging (fMRI) to test whether a different pattern of movementassociated cortical and subcortical activation might contribute to the development of fatigue in patients with MS showed more significant activation of the contralateral primary somatomotor cortex, the ipsilateral rolandic operculum, and the thalamus, indicating impaired interaction between functionally related cortical and subcortical areas in motor fatigue [31].

\section{Primary versus secondary fatigue}

Studies investigating MS-related fatigue distinguish between primary and secondary fatigue. Stankoff et al. state that "in some cases, fatigue may be secondary to depression, cognitive dysfunction, poor sleep, or motor impairment. Nevertheless, for many patients, fatigue exists independently of motor weakness, cognitive, or mood disorders: this primary fatigue...." [16]. Yet the differentiation between primary fatigue (due to MS) and secondary fatigue (due to other diseases, e.g., depression and sleep disorders) is not always clear. The prevalence of restless legs syndrome (RLS) is four times higher in MS patients than in the general population and may be related to spinal cord damage [32, 33]. So, are fatigued MS patients with RLS due to spinal cord lesions suffering from primary or secondary fatigue? What exactly is primary fatigue?

\section{Discrimination between fatigue, motor fatigue, tiredness, and sleepiness}

Figure 1 displays schematically the relationship between primary and secondary fatigue, tiredness, motor fatigue, and sleepiness. Whereas motor fatigue (as one aspect and a specific manifestation of primary fatigue) can be measured objectively by gait recording, mental (cognitive) primary fatigue cannot be distinguished objectively from tiredness and secondary fatigue. Sleepiness is completely different from primary or secondary fatigue or tiredness and can be measured objectively by multiple sleep latency test (MSLT) [20].

\section{Clinical correlates and biological mechanisms Disease course and disability}

Patients with higher disability (according to the Expanded Disability Status Scale (EDSS)) [34] suffer from fatigue more frequently $[35,36]$, and older MS patients as well as those with longer disease duration tend to have more fatigue [36, 37]. Findings vary regarding disease course: Whereas some studies found fatigue to be more prevalent in progressive MS [17, 36, 37], other studies were not able to confirm this relationship [35, 38]. A recent study identified fatigue as an independent predictor of a subsequent MS diagnosis in a cohort of over 100 patients with a clinically isolated syndrome [39].

\section{Cognitive function, neuropsychological deficits, depression, and fatigue}

MS is a complex neurological illness that is often accompanied by neuropsychiatric symptoms. Indeed, major depression is the most common comorbidity in MS [40]. In addition, more than $60 \%$ of MS patients experience 


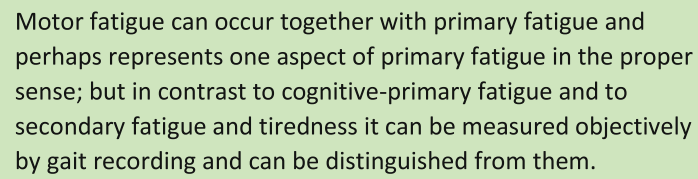
perhaps represents one aspect of primary fatigue in the proper sense; but in contrast to cognitive-primary fatigue and to secondary fatigue and tiredness it can be measured objectively by gait recording and can be distinguished from them.

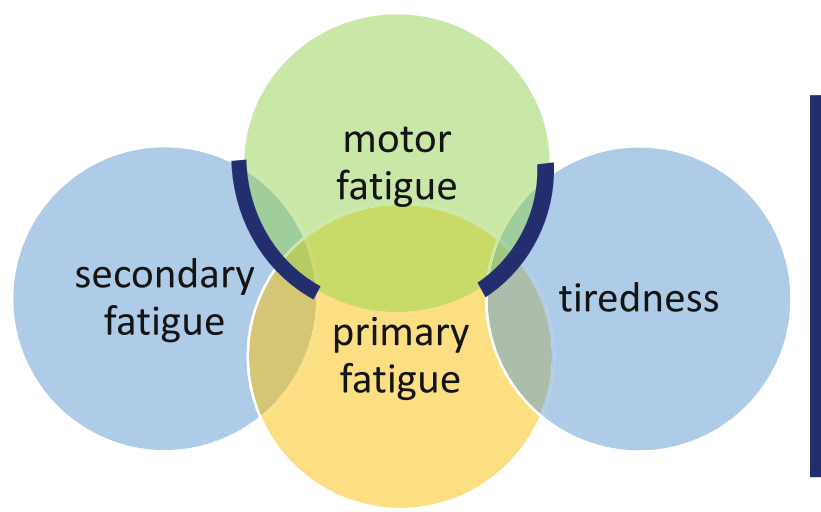

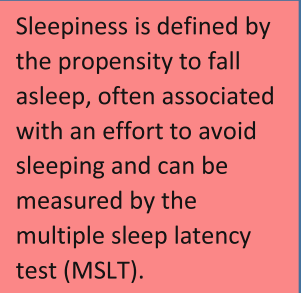
test (MSLT).

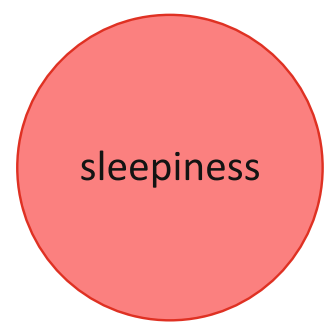

Primary cognitive (mental) fatigue can be distinguished objectively from sleepiness, but not from tiredness or secondary fatigue.

Fig. 1 Distinction between primary fatigue, secondary fatigue, and sleepiness. This figure displays possibilities for distinguishing the primary fatigue from secondary fatigue, tiredness, and sleepiness. Whereas primary motor fatigue can be distinguished objectively from tiredness and secondary fatigue by gait recording, primary cognitive fatigue indeed cannot be distinguished objectively from tiredness and secondary fatigue. Sleepiness can clearly be distinguished from primary and secondary fatigue and motor fatigue and tiredness-as sleepiness can be measured objectively by the multiple sleep latency test

cognitive impairment during the course of their illness, with information processing, executive functioning, attention, and memory most commonly affected [41-47]. Rather than broad cognitive impairment, MS is better characterized by relatively specific, domain-dependent deficits [48]. However, accurate neuropsychological assessment is complicated in MS, because fatigue and depression themselves may have detrimental effects on cognitive function. For instance, poor performance could be confounded by comorbid depressive symptomatology or fatigue, especially as cognitive complaints can be subtle. For example, the Paced Auditory Serial Addition Test (PASAT), often used as a primary tool to assess working memory and processing speed [49], may be vulnerable in repeated neuropsychological assessments to practice effects that obscure the impact of fatigue. More specifically, one study found that while PASAT performance increased with each trial, so did fatigue [50].

Similarly, while subjective fatigue has been associated with reduced cognitive performance $[4,51,52]$, this relationship was not confirmed in other studies [12, 53-56], indicating that the interplay between cognitive dysfunction and fatigue is more complex than could be expected from direct adverse effects of fatigue on quality of life or disability. Indeed, it has been suggested that while cognitive exhaustion may heighten levels of fatigue, severe fatigue does not necessarily reduce cognitive performance [52].

In line with the well-known effects of depression in healthy subjects, and despite earlier negative findings (e.g., [57]), a review has corroborated the association between depression and cognitive function in MS [58]. More specifically, it was shown that high levels of depression mainly affect cognitive functions that are resource intensive, such as attention, working memory, or planning [59-61]. Notably, the adverse effects of depression may be mediated by reductions in processing speed [62], which have also been observed in non-depressed patients with MS [63-65].

An international consortium of MS experts has recommended a battery of tests known as the "Minimal Assessment of Cognitive Function in Multiple Sclerosis" (MACFIMS) for routine monitoring of MS-associated cognitive impairment [66]. The MACFIMS takes roughly $90 \mathrm{~min}$ to administer and assesses language (Controlled Oral Word Association Test), spatial processing (Judgment of Line Orientation Test), learning and memory (California Verbal Learning Test (CVLT)), Brief Visuospatial Memory Test (BVMT), processing speed, and working memory (Symbol Digit Modalities Test, PASAT) as well as executive function (Delis-Kaplan Executive Function System Sorting Test) [66]. Alternatively, 
an abbreviated combination is available that takes approximately $15 \mathrm{~min}$ to complete (Brief International Cognitive Assessment for Multiple Sclerosis (BICAMS)) and includes the SDMT, CVLT-II (first five recall trials only), and BVMT-R (first three recall trials only) [67].

In summary, assessment of neuropsychological impairment in MS patients needs to factor in comorbid depression and fatigue. Particularly, cognitive tests that rely predominantly on processing speed may be vulnerable to bias.

\section{Fatigue and sleep disorders}

The Epworth Sleepiness Scale (ESS) is a screening tool that assesses sleepiness [22], but normal values do not entirely rule out sleep disorders as these are not always associated with sleepiness. Two polysomnographic studies investigating sleep disorders and fatigue in consecutive MS patients have demonstrated a significant relationship between fatigue and sleep disorders $[17,68]$. Interestingly, a significant association existed between the presence of a sleep disorder and MFIS and FSS values, but not between fatigue and ESS values [17]. Both former groups monitored their individual study subjects in an open follow-up study and found that sleep medical treatment significantly reduced fatigue; however, prospective controlled studies are lacking $[69,70]$. In the study by Veauthier et al., 49 out of 66 consecutive MS patients suffered from sleep disorders as confirmed by polysomnography [17]. The most common sleep disorders diagnosed in MS are obstructive sleep apnea (OSA), insomnia, periodic limb movement disorder (PLMD), restless legs syndrome (RLS), and sleep disruption due to nocturia.

Well-established diagnostic criteria that can accurately compare the prevalence of insomnia in the general population compared to MS patients are lacking. A discussion of insomnia in MS is provided in a recent review [2]. Importantly, in the clinical setting, over-the-counter drugs against insomnia (for example, products that contain diphenhydramine) can lead to next-day fatigue [71-73].

As mentioned above, prevalence of RLS is four times higher in MS compared to the general population. MS patients with RLS also show higher EDSS values and significantly reduced cervical cord fractional anisotropy in MRI examinations compared with MS patients without RLS-indicating a more pronounced cervical cord damage in MS patients with RLS [32, 33, 74, 75]. MS patients with more than ten periodic leg movements (PLMs) per hour of REM sleep showed a significantly higher disability measured by the EDSS [33].

With regards to MS and sleep apnea, it is currently unknown whether MS lesions can cause sleep apnea and whether the prevalence of sleep apnea is increased in
MS [2, 76]. In the general population, sleep apnea can cause depression, and conversely, the treatment of sleep apnea by continuous positive airway therapy (CPAP) can be effective in the treatment of depression [77, 78]. This is especially important given the link between fatigue and depression in MS [19, 79]. Studies investigating the impact of treatment for nocturia in MS fatigue are lacking, but only half of MS patients with moderate to severe overactive bladder symptoms are treated with an anticholinergic medication [80].

As polysomnographic assessment is time consuming, defining which patients should undergo the test is critical. In order to develop a screening instrument, we performed a retrospective receiver operating characteristic (ROC) analysis of the investigated MS patients investigated by polysomnography (PSG) - using the MFIS for daytime dysfunction and the Pittsburgh Sleep Quality Index (PSQI) for sleep disturbances [81, 82]. By jointly applying the MFIS cutoff of 34 and the PSQI cutoff of 5 (either MFIS > 34 or PSQI > 5), we achieved a sensitivity of $89.8 \%$ for sleep disorders (specificity $58.8 \%$, positive predictive value $86.3 \%$, negative predictive value $66.7 \%$ ).

\section{Structural and functional MRI correlates}

As structural and diffuse brain damage are detectable from the earliest disease stages, multiple studies have attempted to relate fatigue severity assessed by different questionnaires and sometimes in conjunction with cognitive dysfunction to various neuroimaging findings acquired using structural, functional, and metabolic imaging modalities [83-88]. For example, a magnetic resonance spectroscopy study has indicated decreased $\mathrm{N}$-acetylaspartate-creatine ratios $(\mathrm{NAA} / \mathrm{Cr})$ as a marker of axonal metabolic integrity with increasing fatigue scores, suggesting diffuse and widespread axonal dysfunction as a contributor to fatigue in MS [89]. Structural imaging studies focusing on the quantification of atrophy have reported an association of fatigue severity with atrophy in the thalamus and a number of different cortical gray matter regions (superior frontal and inferior parietal gyrus, parietal lobe) in patients with relapsingremitting MS [90, 91]. Yaldizli et al. found an association between callosal atrophy and fatigue and cognitive performance in a large cohort of MS patients with various disease courses [92], and Nygaard et al. reported a relation between regionally smaller cortical surface areas and volumes and higher depression and fatigue scores in relapsing-remitting MS patients [93]. Although Gobbi et al. did not find an association between white matter atrophy and lesion distribution [94], a previous study by Sepulcre et al. suggested a correlation between T2 lesion load and fatigue severity and between fatigue scores and gray matter atrophy in frontal regions [95]. Damasceno et al. found an association between fatigue severity and 
atrophy in various cortical and gray matter regions; however, after controlling for disability and depression, only caudate and accumbens volumes remained statistically significant (interestingly, the nucleus accumbens is an important mesolimbic structure involved in motivational and reward processes) [96]. Caudate and basal ganglia were also identified as regions related to clinical fatigue by other imaging modalities. A positron emission tomography study by Roelcke et al. found reduced glucose metabolism in the frontal cortex and basal ganglia in MS patients with fatigue [97], and in a resting-state fMRI study, Finke et al. showed that fatigue severity was negatively correlated with functional connectivity of the basal ganglia with the medial prefrontal cortex, precuneus, and posterior cingulate cortex [98]. These connectivity changes suggest-in line with the above mentioned study by Damasceno et al. [96] - that impairment of both motor and non-motor functions of the basal ganglia, which also include reward processing and motivation, is involved in the pathophysiology of fatigue in MS. Another fMRI study applying a motor task by Rocca et al. found decreased activation of various frontal and temporal cortical regions and-importantly-the basal ganglia in MS patients with fatigue, versus MS patients without fatigue and healthy controls. The authors interpreted this as a maladaptation of motor network recruitment and a central contributor to fatigue [99].

Although these and other imaging studies provide interesting data on imaging correlates of fatigue and underscore that dopaminergic structures like the basal ganglia may be significantly related to the perception of fatigue, they merely describe statistical correlations or associations and do not shed light on causality. Moreover, comparability between studies is limited by the heterogeneity of the applied imaging modalities, the clinical cohorts assessed, and the fatigue questionnaires used, which likely at least in part accounts for the discrepancies between study findings. Moreover, in future studies, sleep disorders as a major cause for secondary fatigue and as an important confounder should be ruled out by polysomnography prior to study enrollment.

\section{Inflammation and neuroendocrine abnormalities}

One intriguing observation from animal models and experimental studies in humans is that cytokines and other inflammatory stimuli can induce sickness behavior symptoms, including anorexia, hypoactivity, and hyperthermia, that resemble some aspects of fatigue [100-102]. This socalled sickness behavior has therefore been proposed as a pathobiological model of fatigue in the context of inflammatory disorders such as MS [103]. However, clinical studies applying this model in the specific context of MS have yielded mixed results. Circulating levels of several inflammatory markers such as interleukin-2 (IL-2), neopterin, ICAM-1 (intercellular adhesion molecule 1), and $\mathrm{C}$-reactive protein (CRP) were not correlated with fatigue [104, 105]. In contrast, two studies examining proinflammatory cytokines such as TNF $\alpha$ (tumor necrosis factor alpha) (but not interferon- $\gamma$ (IFN $\gamma$ )) mRNA in lymphocytes [106] and TNF $\alpha$ and IFN $\gamma$ protein production after in vitro stimulation [107] reported positive correlations with fatigue. A study subsequent to the latter also found increased intracellular in vitro production of IFN $\gamma$ that correlated fatigue [108]. These cytokines did not yield significant associations with fatigue scores in a more comprehensive serum cytokine screen, which however suggested an association of fatigue with interleukin-6 (IL-6) [109].

Beyond inflammatory markers, several studies have also investigated the relationship between alterations in neuroendocrine systems, such as the hypothalamo-pituitaryadrenal (HPA) axis, and MS-related fatigue. Again, study findings were mixed. Whereas Gottschalk et al. found a higher activity of the HPA axis in MS fatigue patients, as evidenced by significantly increased adrenocorticotropin (ACTH) concentrations, Heesen et al. reported that HPAaxis feedback-regulation (as determined by the Dex-CRH suppression test) axis activity was not related to fatigue $[107,110]$. Resting levels of cortisol (as measured by a single midday blood sample) were also not associated with fatigue in another study [111]. More recently, one study reported an association of fatigue in relapsing-remitting MS (RR-MS) with lower waking cortisol levels and an increased response to awakening (cortisol awakening response (CAR)), indicating that cortisol could play a role in the perception of fatigue [112], but two studies assessing the circadian slope of cortisol secretion did not find an association with MS fatigue $[108,112]$.

In summary, while the role of inflammation in the pathobiology of "fatigue-like" symptoms is well supported by animal models and experimental studies in humans, no individual immune or neuroendocrine markers have consistently been associated with fatigue in MS. Some of this might be due to the large heterogeneity of markers, challenge paradigms, and the definition of fatigue used in each particular study. Moreover, in light of the abovementioned high prevalence of sleep disorders in MS fatigue, future studies investigating the neuroinflammatory and neuroendocrine aspects of MS-associated fatigue should take care to apply polysomnography to exclude possible bias resulting from sleep disorders as confounder.

\section{Methodical limitations and further research direction}

Diversity between study cohorts (e.g., with or without secondary progression, level of disability, treatment naïve or not) is a long-standing problem hampering definitive interpretation of research into MS as a whole. The investigation of MS-related fatigue is additionally complicated by a 
lack of standardization between fatigue scales and, even more seriously, by the fact that the potential confounders (sleep disorders and drug side effects) are not excluded as a matter of course. Definitively identifying mutual relationships between distinct parameters (imaging or depression or disease course or cognitive dysfunction or sleep disorders or inflammation and fatigue) across different studies becomes neigh on impossible. To date, not one study into MS-related fatigue has examined all parameters and excluded all known confounders. Such a task would be even more difficult in the context of urgently needed large multicenter studies.

\section{Treatment of MS fatigue}

\section{Immune therapy and fatigue}

The same methodical limitations apply to the published data on the impact of MS treatment on fatigue. The lack of studies investigating the influence of existing MS therapies on MS fatigue as a primary endpoint and the influence of other confounders, such as age, disease course and duration, questionnaires used, medication, comorbid disorders (e.g., depression), and the lack of a control group in most studies, have hampered insight into the effect of disease-modifying therapies on MSrelated fatigue. However, a number of studies suggest that beta interferons and glatiramer acetate (GA) reduce fatigue (with GA treatment potentially more effective) [113-116]. The effect of natalizumab on fatigue varied between studies $[117,118]$. Whereas Penner et al. found that fatigue levels remained constant or decreased in the majority of patients after 1 year of natalizumab treatment, Kunkel et al. found no significant changes, although this may have been due to the study's small cohort size [117, 118].

Some limited results show that fingolimod might improve fatigue after changing from beta interferon to fingolimod (but not from GA) [119, 120]. However, no evidence exists that teriflunomide, dimethyl fumarate, or alemtuzumab improve fatigue [121-123]. In fact, one study identified fatigue as a side effect of dimethyl fumarate treatment [122].

\section{Management strategies recommended by the MS Council} As fatigue is not specific or unique to MS [124-126], in 1998, the MS Council for Clinical Practice Guidelines recommended performing blood tests and evaluating comorbid medical conditions, iatrogenic factors, depression or psychological distress, sleep disturbances, and, where applicable, as next diagnostic step sleep studies (polysomnography and multiple sclerosis latency test) [9]. Chronic obstructive pulmonary disease (COPD) should also be excluded [9]. After ruling out or addressing any comorbid medical conditions, drug therapy, (aerobic) exercise, and, among others, self-management strategies were recommended. Self-management strategies included activities such as cessation of smoking, modifying dietary habits, optimizing time management, adjusting activity levels, taking naps, consumption of cool beverages, cool showers and baths for heat intolerance, exercise programs, or engaging in relaxation exercises.

\section{Drug therapy}

One recently published trial (alfacalcidol versus placebo) showed a significant reduction of fatigue under therapy with alfacalcidol (an active vitamin D3 metabolite requiring activation in the liver) [127]. Further studies are needed in order to confirm this effect. Apart from vitamin $\mathrm{D}$, in recent studies, modafinil, amantadine, carnitine, or pemoline [16, 128-136] have generally not been found to be effective in treating MS-related fatigue. Our review of the literature found six meta-analyses of the randomized controlled trials (modafinil, amantadine, carnitine, and pemoline) $[16,128,130,131,133-135,137-140]$. Whereas one meta-analysis investigating three studies published before 1996 found a significant effect of amantadine superior to placebo [141], five other meta-analyses analyzing these three studies and further recent studies did not report any significant effect of the investigated drugs [129, 136, 142-144]. One study, however, did find a significant improvement of fatigue under treatment with carnitine compared to amantadine [140]. Aspirin was found to be an effective treatment for fatigue in another study [145], although this was countered by a subsequent study comparing aspirin with amantadine treatment [130].

\section{Motor fatigue and fampridine}

4-Aminopyridine (dalfampridine, fampridine), a potassium channel blocker, is approved by the US Food and Drug Administration, Health Canada, and the European Medicines Agency as a treatment for MS-related walking ability [146]. Clinical trials have shown improvement in walking speed compared to placebo (the percentage of MS patients with an improvement in 6-min walk test of $>20 \%$ (45.1\%) was significantly greater with dalfampridine relative to placebo $(14.3 \%))[146,147]$.

Furthermore, two studies showed that fampridine improves MS fatigue as assessed using the visual analog scale (VAS), the MFIS, and the FSS [148, 149]. Treatment with fampridine should be stopped immediately in patients presenting with hypersensitivity symptoms, such as swollen face, mouth, lips, throat or tongue, reddening or itching of the skin, chest tightness and breathing problems, and seizures (up to 1 in 100 people). A number of other unpleasant but harmless side effects exist, including urinary tract infection $(>10 \%)$ and dizziness, headache, sleep disturbances, and anxiety $(<10 \%)$. Fampridine is contraindicated in patients with a creatinine clearance lower than $80 \mathrm{ml} / \mathrm{min}$, and therefore, renal function should be monitored. Initial prescription 
should be limited to 2 weeks of therapy, which is the duration needed to assess clinical benefit. Extension of treatment should be subject to improvement as assessed by a timed walking test. If no improvement is observed at this point, the fampridine treatment should be discontinued. Fampridine is contraindicated during pregnancy.

\section{Fatigue management interventions, rehabilitation intervention and cognitive behavioral therapy}

Rehabilitation (exercise or physical therapy, educational interventions such as mindfulness training, selfmanagement program, vestibular rehabilitation) and cognitive behavioral therapy (CBT) are significantly effective against MS-related fatigue [136, 150-153]. Moreover, internet-based CBT has been investigated and could play a greater role in the future [154, 155].

A 2014 systematic review and meta-analysis by Asano and Finlayson compared pharmacotherapy, exercise, and educational interventions for MS-related fatigue [136], suggesting that the eight reports of educational approaches yielded a significant overall effect with an effect size of 0.54 (95\% CI $0.30-0.77, p<0.001$ ). In particular, the three trials that used CBT exhibited the largest effect within the educational intervention subsection of the review [154-156]. One additional trial has been published since the above review combining CBT with energy conservation. Here, too, significantly reduced fatigue was found (standardized effect size 0.54). A follow-up analysis found that some of the effects were maintained at 12 months post-trial [157].

Overall, strong evidence exists that educational interventions have a definitive moderate ability to reduce MS-related fatigue. It should be noted that the studies surveyed were generally combined elements of CBT, mindfulness, skill training, and educational components. Published evidence to date suggests that CBT-based interventions are the most effective elements of a fatigue management program (see Table 1). Finally, the settings of these interventions also vary from group to one-on- one sessions or from in-person to telephone or internet intervention. The available trials (see Table 1) suggest that individual intervention might yield larger effects than group interventions; however, this has not been formally studied to date. For the time being, the setting used should be based on the resources available and the specific needs and requirements of the patient population. Remote access options like telephone or Internet sessions might be particularly suitable for patients with mobility problems or patients in rural areas.

\section{Treatment of underlying sleep disorders}

The first step to addressing MS-related fatigue is diagnosing and treating any underlying sleep disorders. Two studies of sleep disorders and fatigue in consecutive MS patients have demonstrated a significant relationship between fatigue and sleep disorders $[17,68]$. In the study by Veauthier et al., 96\% of fatigued MS patients were suffering from a sleep disorder [17]. Sleep disorders are frequent in MS and have been significantly associated with higher MFIS values. MS patients suffering from sleep disorders show increased MFIS values compared to MS patients who are not suffering from sleep disorders ( $\mathrm{SD} \pm 42.8$ versus $\pm 20.5, p<0.001$ ) [17]. Besides depression and disability, sleep disturbances decrease health-related quality of life (HRQoL) [158, 159]. Although OSA is a prevalent pathological condition and represents an increased risk for cardiovascular diseases, a majority of patients remain undiagnosed [160, 161]. In particular, MS patients suffering from comorbid obstructive sleep apnea (OSA) or insomnia showed significantly decreased HRQoL for the "sleep" area (sleep subscale). But furthermore, OSA and insomnia patients show increased values in the "energy" and "emotional" subscales as well indicating that sleep disorders lead to impaired daytime functioning (and in OSA patients also for "physical abilities") [158].

The most important sleep disorders in this context are OSA, insomnia, periodic limb movement disorder (PLMD), restless legs syndrome (RLS), and nocturia

Table 1 Trials using educational interventions in MS-related fatigue

\begin{tabular}{|c|c|c|c|}
\hline & Sample size & Intervention & $\begin{array}{l}\text { Effect size (according to meta-analysis } \\
\text { by Asano and Finlayson) }\end{array}$ \\
\hline Mohr et al. 2003 [156] & 60 & CBT (individual sessions) & $0.80(0.19-1.42)$ \\
\hline Mathiowetz et al. 2005 [188] & 169 & $\begin{array}{l}\text { Fatigue management program (energy conservation course) } \\
\text { (group sessions) }\end{array}$ & $0.42(0.08-0.76)$ \\
\hline Kos et al. 2007 [189] & 51 & Multidisciplinary fatigue management program (group sessions) & $-0.16(-0.72$ to 0.38$)$ \\
\hline Van Kessel et al. 2008 [155] & 72 & CBT (individual and phone sessions) & $0.99(0.50-1.48)$ \\
\hline Grossman et al. 2010 [150] & 150 & Mindfulness (group sessions) & $0.42(0.09-0.74)$ \\
\hline Hugos et al. 2010 [190] & 30 & Fatigue management program (group sessions) & $0.43(-0.29$ to 1.57$)$ \\
\hline Finlayson et al. 2011 [191] & 190 & Fatigue management program (phone sessions) & $0.53(0.19-0.86)$ \\
\hline Moss-Morris et al. 2012 [154] & 40 & CBT (online + phone sessions) & $1.11(0.43-1.78)$ \\
\hline Thomas et al. 2013 [157] & 164 & CBT + energy effectiveness training (group) & 0.54 (not included in meta-analysis) \\
\hline
\end{tabular}


[2]. In two open follow-up studies, the treatment of an underlying sleep disorder (continuous positive airway pressure (CPAP) for OSA, drug therapy and CBT for insomnia, and drug therapy for RLS and PLMD) significantly reduced fatigue, but prospective controlled studies are lacking $[69,70]$.

Many studies investigating fatigue have used the Epworth Sleepiness Scale (ESS) as a screening tool for sleep disorders $[16,22,162]$. That is not entirely correct. The ESS is a diagnostic instrument for sleepiness, not fatigue, and is especially recommended in the context of hypersomnia, OSA, and narcolepsy. A part of patients suffering from sleep disorders feel sleepy, but a significant proportion does not feel sleepy but rather fatigued. Therefore, the ESS is not a suitable questionnaire for all sleep disorders. In insomnia and other sleep disorders like RLS or PLMD, specific questionnaires are recommended: the Pittsburgh Sleep Quality Index (PSQI) or the Insomnia Severity Index (ISI) for insomnia and the RLS Diagnostic
Index (RLS-DI) for RLS [81, 163, 164]. These questionnaires cannot reflect the complex symptoms of sleep disorders and are only screening tools-clinical interview by a sleep expert and objective testing (polysomnography) are the gold standard of sleep medical diagnosis.

\section{The Berlin Treatment Algorithm}

It is one thing to recommend the treatment of underlying sleep disorders in this issue in general, but another to say which patient has to be sent to the sleep specialist or sleep laboratory. Because of the complexity of the issue and due to the fact that clinicians need some practical instructions, the discussion of the different treatment options does not replace the need for a practical guide with specific procedures and measures. We would like to take the opportunity to introduce our Berlin Treatment Algorithm of MS fatigue, which we developed in the last years. Figure 2 outlines the treatment algorithm.

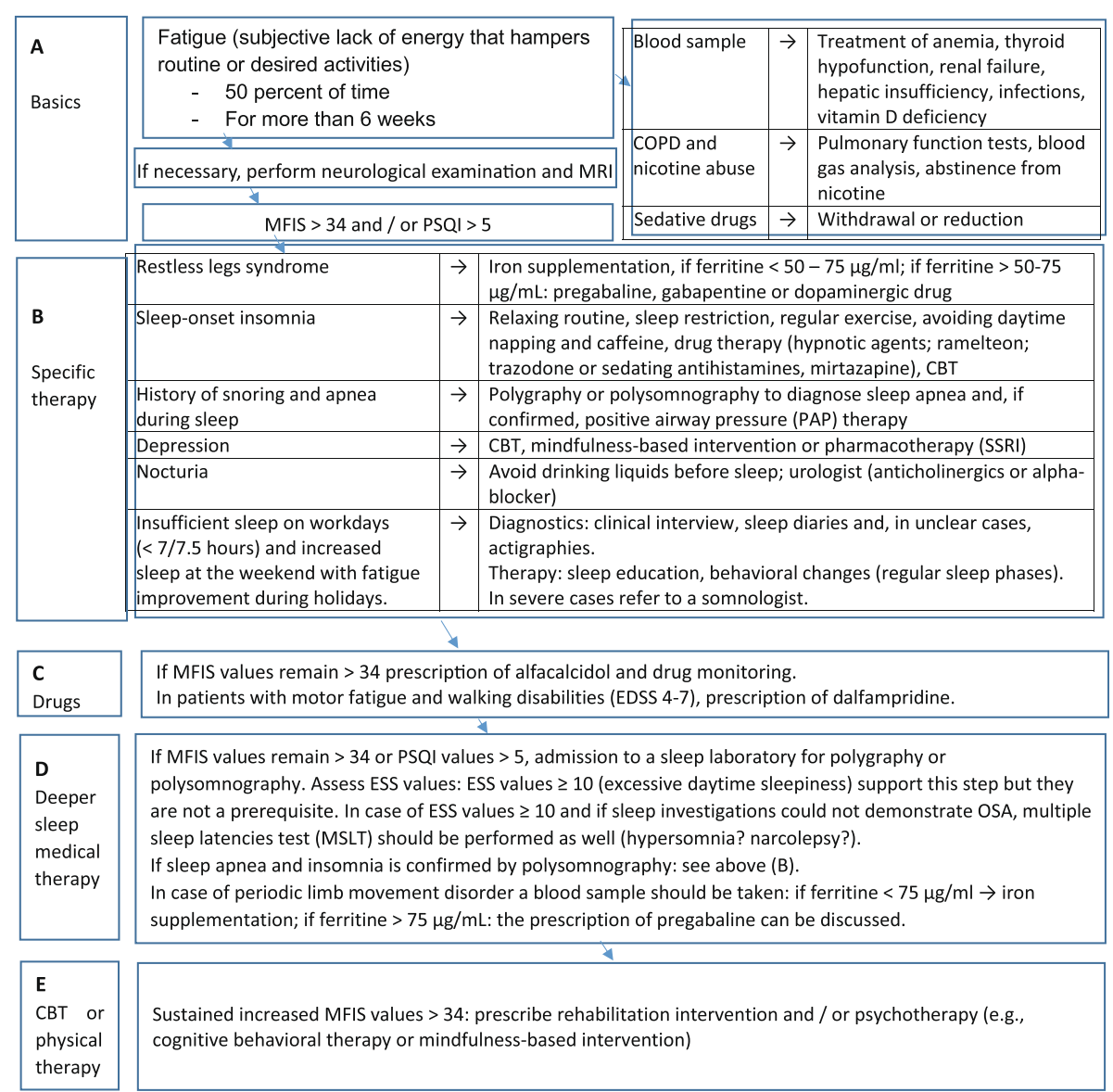

Fig. 2 The Berlin Treatment Algorithm. Please note: Restless legs syndrome can be diagnosed on the basis of the following four minimal criteria: an urge to move the legs (usually accompanied by uncomfortable sensations), which begin or worsen during rest and are relieved by movement predominantly in the evening or night. Depression can be diagnosed by structured interviews. Self-report scales (e.g., Beck Depression Inventory (BDI)) can be useful to screen for depression. Abbreviations: MFIS Modified Fatigue Impact Scale, PSQI Pittsburgh Sleep Quality Index, ESS Epworth Sleepiness Scale, COPD chronic obstructive pulmonary disease, SSRIs selective serotonin reuptake inhibitors, CBT cognitive behavioral therapy 


\section{Phase A: basic recommendations}

The Berlin Treatment Algorithm follows the recommendations of the MS Council for Clinical Practice Guidelines as a first step: As an initial step, blood tests should be performed to rule out anemia, thyroid dysfunction, renal and hepatic insufficiency, vitamin D deficiency, and infections. In cases of possible COPD (due to smoking), pulmonary function tests and blood gas analysis are also recommended. At this stage, medical history questionnaires should also address a patient's use of sedative drugs, including over-the-counter medicines, which might worsen fatigue. Weaning or reducing patient consumption of such drugs would be the next necessary step. If the patient has recently been suffering from fatigue, a neurological examination should be performed to rule out relapse or disease progression and an MRI should be performed in order to assess radiographic disease activity [165]. Once the above confounders have either been addressed or excluded, the patient should fill out the MFIS and the PSQI. Then, all patients with higher MFIS values $>34$ and/or PSQI values $>5$ should enter the next phase.

\section{Phase B: specific therapy}

At this stage, possible causes of fatigue should be identified by a diagnostic interview. The latter should include questions about both current and past fatigue symptoms and focus mainly on determining whether nocturia, depression, and sleep disorders (OSA, insomnia, RLS, behaviorally induced insufficient sleep syndrome (BIISS)) play a role [21].

Restless legs syndrome RLS is defined by an urge to move the legs, usually accompanied by uncomfortable and unpleasant sensations in the legs, which is partially or totally relieved by movement. The discomfort begins or worsens during periods of rest or inactivity and in the evening or at night on condition that its occurrence is not solely accounted for as symptoms primary to another medical or a behavioral condition [166]. RLS is often misdiagnosed in MS patients, and RLS-associated symptoms are often misinterpreted as spasticity in more disabled patients.

Treatment of RLS symptoms consists of iron supplementation, if ferritin serum levels are lower than $75 \mathrm{mcg} / \mathrm{l}$, and dopaminergic drugs [167-169]. Pregabalin is effective against RLS symptoms as well, but it is not approved in some countries for the treatment of RLS [170].

The questionnaire Restless Legs Syndrome Diagnostic Index (RLS-DI) is used as a screening tool; however, this cannot replace a diagnostic interview by a sleep expert. The International RLS Study Group (IRLSSG) rating scale should be used for the assessment of the response to therapy $[164,171]$.

Insomnia Whereas impaired sleep maintenance can be an unspecific symptom of sleep disorders in general
(OSA, insomnia, and others), delayed sleep onset with prolonged sleep latencies before falling asleep is a clear indication for sleep-onset insomnia. Such patients can be treated with sleep restriction therapy and sleep hygiene education, relaxing routine within an hour before bedtime, regular exercise, avoiding daytime napping, and late heavy meals $[172,173]$. Sleep restriction is an easy and very efficacious therapy against sleep-onset insomnia [174]. Prescription and over-the-counter drug therapies include short-acting non-benzodiazepine sedative-hypnotic agents; ramelteon, a melatonin receptor agonist; trazodone; antidepressants; and sedating antihistamines [175]. Thyroid hyperfunction should be ruled out, and coffee should be avoided (in particular, in the afternoon and evening).

Behaviorally induced insufficient sleep syndrome Sleepiness may be caused by behaviorally induced insufficient sleep syndrome (BIISS), which can only be diagnosed by a detailed medical history [21]. Doctors should not only ask about sleep problems, but also about time spent in bed (currently and in the past, on workdays, and at weekends) and about fatigue severity during workdays and during holidays. Longer sleep times on the weekend or during holidays point to BIISS. Sleep diaries or actigraphy may be helpful. In severe cases, referral to a sleep expert can be necessary [167].

Obstructive sleep apnea If patients suffer from sleepiness (especially in case of ESS values $\geq 10$ ), they should be referred to a sleep specialist or admitted to a sleep laboratory, for assessment of possible narcolepsy, hypersomnia, or (more frequently) obstructive sleep apnea; symptoms of the latter include snoring, non-restorative sleep, morning headaches, dry mouth, nocturnal gasping or apnea, cardiovascular diseases, increased neck circumference, obesity, and a family history of OSA [20].

Nocturia Patients with nocturia ( $\geq 2$ times per night) should be referred to a urologist, and a treatment with an anticholinergic or alpha-blocker should be considered $[80,176]$.

Depression Depression should be diagnosed using current criteria (e.g., Diagnostic and Statistical Manual of Mental Disorders, Fifth Edition (DSM-V) [177] or the International Statistical Classification of Diseases and Related Health Problems (ICD-10) [178]). This should ideally be done using standardized tools such as structured diagnostic interviews by experienced clinicians. Self-report scales such as the Beck Depression Inventory (BDI-II) can be used as a screening tool to identify patients requiring further diagnostic work-up. Recommended cutoffs for the general population are BDI values $>13$ in treated depressed patients and BDI-II $>21$ 
in treatment naïve patients [179]. For MS patients, these cutoffs might need to be adjusted to optimize sensitivity and specificity, depending on the clinical context $[13,180]$. As a brief screening tool, the twoitem approach by Mohr and colleagues has been recommended by the American Academy of Neurology (AAN) task force [156, 181].

In cases of depression, the treatment should include tailored treatment algorithms and multimodal approaches and a comprehensive treatment should include primarily psychotherapy and optionally pharmacotherapy [182]. Selective serotonin reuptake inhibitors (SSRIs) are generally considered to be an effective and welltolerated first-line treatment [183]. The guidelines published by the AAN did not recommend antidepressant pharmacotherapy for depression in MS due to a lack of conclusive evidence; however, more recently, a metaanalysis reported overall beneficial effects [181, 184, 185]. Cognitive behavioral therapy and mindfulness-based interventions have shown efficacy in improving depressive disorders in MS [181, 185].

\section{Phase C: drug therapy}

Fampridine prescribed for walking ability may be effective against fatigue as well, and one recent published randomized controlled trial (RCT) showed a substantial improvement of fatigue under therapy with vitamin D (alfacalcidol, if blood calcium levels are not higher than $10.5 \mathrm{mg} / \mathrm{dl}$ )-but despite the substantial psychosocial burden of MS-related fatigue, there are no pharmacological treatments formally approved by regulatory authorities [127, 129, 136, 149, 186]. Despite poor evidence, individual attempts to improve fatigue with modafinil, amantadine or carnitine may be undertaken.

\section{Phase D: intensified sleep medical therapy}

Patients without improvement in fatigue following measures undertaken during the preceding phases should be admitted to a sleep laboratory in order to diagnose or exclude other underlying sleep disorders according to the ICSD-3 (International Classification of Sleep Disorders, Third Edition), which cannot be diagnosed by the diagnostic interview and questionnaires alone (for example, sleep-related breathing disorders including central apnea, obstructive sleep apnea, obesity hypoventilation syndrome, periodic limb movement disorder, parasomnia, insomnia) [20]. In some cases, a specified sleep medical treatment (continuous positive airway pressure (CPAP) or drug therapy) can be started and fatigue may improve.

\section{Phase E: rehabilitation and cognitive behavioral therapy}

If fatigue persists, patients should participate in exercise therapy (aerobic exercise or resistance training) at least once a week or CBT $[9,183]$. This can be undertaken individually or as part of a group therapy and would be facilitated by tertiary MS centers collaborating with physical therapists or physical medicine and rehabilitation specialists in order to develop interned-based and cost-effective interventions.

\section{Outlook}

In the future, novel approaches such as smartphonebased applications might play a role in measuring performance and patient-reported outcomes and improving fatigue by self-management strategies [187].

\section{Conclusions}

The treatment of MS-related fatigue remains a challenging task, particularly due to the lack of a proven pharmacological therapy. However, many other therapeutic strategies have been shown to be effective in the treatment of MS-related fatigue. Therefore, a comprehensive approach including self-management strategies, rehabilitation, CBT, and the treatment of underlying sleep disorders and potentially other comorbidities is reasonable. The aim of the algorithm presented is to provide the treating physicians with a practical guide facilitating diagnosis and treatment of MS fatigue in individual patients.

\section{Expert recommendation}

Personalized medicine is a promising new therapeutic strategy in order to treat MS-related fatigue. The treatment of fatigue should be tailored to the MS patients-taking into account comorbid disorders such as RLS, insomnia, depression, history of snoring and sleep apnea, nocturia, and sleep deprivation as well as side effects of the medication. Patients with high MFIS or PSQI values indicating a high risk of sleep disorders should be investigated by polygraphy or polysomnography.

\footnotetext{
Abbreviations

AAN: American Academy of Neurology; ACTH: Adrenocorticotropic hormone; BDI-II: Beck Depression Inventory; BICAMS: Brief International Cognitive Assessment for Multiple Sclerosis; BIISS: Behaviorally induced insufficient sleep syndrome; BVMT: Brief Visuospatial Memory Test; CAR: Cortisol awakening response; CBT: Cognitive behavioral therapy; COPD: Chronic obstructive pulmonary disease; CPAP: Continuous positive airway pressure; CRP: C-reactive protein; CVLT: California Verbal Learning Test; DSM$\checkmark$ : Diagnostic and Statistical Manual of Mental Disorders, Fifth Edition; EDSS: Expanded Disability Status Scale; ESS: Epworth Sleepiness Scale; FIS: Fatigue Impact Scale; fMRI: Functional magnetic resonance imaging; FSMC: Fatigue Scale for Motor and Cognitive Functions; FSS: Fatigue Severity Scale; GA: Glatiramer acetate; HPA: Hypothalamo-pituitary-adrenal; HRQOL: Health-related quality of life; ICAM-1: Intercellular adhesion molecule 1; ICD-10: International Statistical Classification of Diseases and Related Health Problems; ICSD-3: International Classification of Sleep Disorders, Third Edition; IFNy: Interferon-ү; IL-2/IL-6: Interleukin-2/-6; MACFIMS: Minimal Assessment of Cognitive Function in Multiple Sclerosis; MFIS: Modified Fatigue Impact Scale; MS: Multiple sclerosis; MSLT: Multiple sleep latency test; MSQLI: Multiple Sclerosis Quality-of-Life Inventory; NAA/Cr: N-acetylaspartatecreatine ratio; OSA: Obstructive sleep apnea; PASAT: Paced Auditory Serial Addition Test; PLMD: Periodic limb movement disorder; PSG: Polysomnography; PSQI: Pittsburgh Sleep Quality Index; RCT: Randomized controlled trial; RLS: Restless legs syndrome; RLS-DI: RLS
} 
Diagnostic Index; ROC: Receiver operating characteristic; RR-MS: Relapsingremitting MS; SSRIs: Selective serotonin reuptake inhibitors; TNFa: Tumor necrosis factor alpha

\section{Acknowledgements}

Not applicable.

\section{Funding}

None.

Availability of data and materials

The data and articles mentioned in this review are published on PubMed.

\section{Authors' contributions}

CV developed the Berlin Treatment Algorithm, was responsible for the study design, and wrote the text, excluding the sections on neuroimaging, neuroinflammation, and neuropsychology. He reviewed the literature and the neuroimaging, neuroinflammation, and neuropsychology section and is responsible for final approval of the version to be published, together with FP. He is accountable for all aspects of the work and ensuring that questions of accuracy or integrity of any part of the work are appropriately investigated and resolved. $\mathrm{HH}$ wrote the chapter on neuropsychology and participated in editing the article. SG wrote the chapters on neuroinflammation/ neuroendocrinology, depression, and behavioral interventions and participated in editing the article. FP contributed substantially to the concept and design, contributed to the drafting and revision of the manuscript, and wrote the neuroimaging chapter. Together with $\mathrm{CV}$, he is responsible for final approval of the version to be published. He is accountable for all aspects of the work and ensuring that questions of accuracy or integrity of any part of the work were appropriately investigated and resolved. Authors read and approved the final manuscript.

\section{Competing interests}

The authors declare that they have no competing interests.

\section{Consent for publication}

Not applicable

\section{Ethics approval and consent to participate}

Not applicable

\section{Author details}

${ }^{1}$ Interdisciplinary Center for Sleep Medicine, Charité - Universitätsmedizin Berlin, Charitéplatz 1, 10117 Berlin, Germany. ${ }^{2}$ NeuroCure Clinical Research Center, Charité - Universitätsmedizin Berlin, Charitéplatz 1, 10117 Berlin, Germany. ${ }^{3}$ Department of Psychiatry and Psychotherapy, Charité Universitätsmedizin Berlin, Hindenburgdamm 30, 12203 Berlin, Germany. ${ }^{4}$ Institute of Neuroimmunology and Multiple Sclerosis (INIMS), Center for Molecular Neurobiology (ZMNH), University Medical Center Hamburg-Eppendorf, 20251 Hamburg, Germany. ${ }^{5}$ Clinical and Experimental Multiple Sclerosis Research Center, Department of Neurology, Charité Universitätsmedizin Berlin, 10117 Berlin, Germany. ${ }^{6}$ Experimental and Clinical Research Center, Max Delbrück Center for Molecular Medicine and Charité Universitätsmedizin Berlin, Berlin, Germany.

\section{Received: 27 August 2016 Accepted: 21 October 2016}

Published online: 24 November 2016

\section{References}

1. Borisow N, Döring A, Pfueller CF, Paul F, Dörr J, Hellwig K. Expert recommendations to personalization of medical approaches in treatment of multiple sclerosis: an overview of family planning and pregnancy. EPMA J. 2012;3(1):9.

2. Veauthier C, Paul F. Sleep disorders in multiple sclerosis and their relationship to fatigue. Sleep Med. 2014;15(1):5-14.

3. Konieczka K, Koch S, Binggeli T, Schoetzau A, Kesselring J. Multiple sclerosis and primary vascular dysregulation (Flammer syndrome). EPMA J. 2016;7(1). Available from: http://epmajournal.biomedcentral.com/articles/10.1186/ s13167-016-0062-6

4. Krupp LB, Alvarez LA, LaRocca NG, Scheinberg LC. Fatigue in multiple sclerosis. Arch Neurol. 1988;45(4):435-7.
5. Berger JR, Pocoski J, Preblick R, Boklage S. Fatigue heralding multiple sclerosis. Mult Scler. 2013;19(11):1526-32.

6. Chua AS, Glanz BI, Guarino AJ, Cook SL, Greeke EE, Little GE, et al. Patientreported outcomes in multiple sclerosis: relationships among existing scales and the development of a brief measure. Mult Scler Relat Disord. 2015;4(6):598-606.

7. Moore P, Harding KE, Clarkson H, Pickersgill TP, Wardle M, Robertson NP. Demographic and clinical factors associated with changes in employment in multiple sclerosis. Mult Scler. 2013;19(12):1647-54.

8. Coyne KS, Boscoe AN, Currie BM, Landrian AS, Wandstrat TL. Understanding drivers of employment changes in a multiple sclerosis population. Int J MS Care 2015:17(5):245-52

9. Paralyzed Veterans of America, editor. Fatigue and multiple sclerosis: evidence-based management strategies for fatigue in multiple sclerosis. Washington, DC; 1998. Available from: http://www.pva.org/site/apps/ka/ec/ product.asp?c=aj|RK9NJLcJ2E\&b=6423003\&en= 4dLxHFOfF3LGLPOiF2IDLLNsEhJIKLMkEbKJJWOAJrE\&ProductID=907097

10. Veauthier C, Paul F. Therapie der Fatigue bei Multipler Sklerose, ein Behandlungsalgorithmus. Nervenarzt. 2016, doi:10.1007/s00115-016-0128-7.

11. Krupp LB, LaRocca NG, Muir-Nash J, Steinberg AD. The fatique severity scale. Application to patients with multiple sclerosis and systemic lupus erythematosus. Arch Neurol. 1989:46(10):1121-3.

12. Fisk JD, Ritvo PG, Ross L, Haase DA, Marrie TJ, Schlech WF. Measuring the functional impact of fatigue: initial validation of the fatigue impact scale. Clin Infect Dis. 1994;18 Suppl 1:S79-83.

13. Fischer JS, LaRocca NG, Miller DM, Ritvo PG, Andrews H, Paty D. Recent developments in the assessment of quality of life in multiple sclerosis (MS). Mult Scler. 1999;5(4):251-9.

14. Veauthier C. Younger age, female sex, and high number of awakenings and arousals predict fatigue in patients with sleep disorders: a retrospective polysomnographic observational study. Neuropsychiatr Dis Treat. 2013;9:1483.

15. Flachenecker $P$, Kümpfel T, Kallmann B, Gottschalk M, Grauer O, Rieckmann P, et al. Fatigue in multiple sclerosis: a comparison of different rating scales and correlation to clinical parameters. Mult Scler. 2002;8(6):523-6.

16. Stankoff B, Waubant E, Confavreux C, Edan G, Debouverie M, Rumbach L, et al. Modafinil for fatigue in MS: a randomized placebo-controlled doubleblind study. Neurology. 2005;64(7):1139-43.

17. Veauthier C, Radbruch H, Gaede G, Pfueller C, Dorr J, Bellmann-Strobl J, et al. Fatigue in multiple sclerosis is closely related to sleep disorders: a polysomnographic cross-sectional study. Mult Scler. 2011;17(5):613-22.

18. Penner I, Raselli C, Stocklin M, Opwis K, Kappos L, Calabrese P. The Fatigue Scale for Motor and Cognitive Functions (FSMC): validation of a new instrument to assess multiple sclerosis-related fatigue. Mult Scler. 2009:15(12):1509-17.

19. Greim B, Benecke R, Zettl UK. Qualitative and quantitative assessment of fatigue in multiple sclerosis (MS). J Neurol. 2007;254(S2):1158-64.

20. American Academy of Sleep Medicine, editor. International Classification of Sleep Disorders. 3rd ed. Darien, IL: American Academy of Sleep Medicine; 2014

21. Marti I, Valko PO, Khatami R, Bassetti CL, Baumann CR. Multiple sleep latency measures in narcolepsy and behaviourally induced insufficient sleep syndrome. Sleep Med. 2009;10(10):1146-50

22. Johns MW. Reliability and factor analysis of the Epworth Sleepiness Scale. Sleep. 1992;15(4):376-81

23. Popp RFJ, Fierlbeck AK, Knüttel H, König N, Rupprecht R, Weissert R, et al. Daytime sleepiness versus fatigue in patients with multiple sclerosis: a systematic review on the Epworth sleepiness scale as an assessment tool. Sleep Med Rev. 2016, doi:10.1016/j.smrv.2016.03.004

24. Aguillard RN, Riedel BW, Lichstein KL, Grieve FG, Johnson CT, Noe SL. Daytime functioning in obstructive sleep apnea patients: exercise tolerance, subjective fatigue, and sleepiness. Appl Psychophysiol Biofeedback. 1998:23(4):207-17.

25. Hossain JL, Ahmad P, Reinish LW, Kayumov L, Hossain NK, Shapiro CM. Subjective fatigue and subjective sleepiness: two independent consequences of sleep disorders? J Sleep Res. 2005;14(3):245-53.

26. Kluger BM, Krupp LB, Enoka RM. Fatigue and fatigability in neurologic illnesses: proposal for a unified taxonomy. Neurology. 2013;80(4):409-16.

27. Severijns D, Octavia JR, Kerkhofs L, Coninx K, Lamers I, Feys P. Investigation of fatigability during repetitive robot-mediated arm training in people with multiple sclerosis. PLoS One. 2015:10(7):e0133729.

28. Behrens J, Pfüller C, Mansow-Model S, Otte K, Paul F, Brandt AU. Using perceptive computing in multiple sclerosis-the Short Maximum Speed Walk test. J Neuroeng Rehabil. 2014;11:89. 
29. Behrens JR, Mertens S, Krüger T, Grobelny A, Otte K, Mansow-Model S, et al. Validity of visual perceptive computing for static posturography in patients with multiple sclerosis. Mult Scler. 2016;22(12):1596-1606.

30. Sehle A, Mündermann A, Starrost K, Sailer S, Becher I, Dettmers C, et al. Objective assessment of motor fatigue in multiple sclerosis using kinematic gait analysis: a pilot study. J Neuroeng Rehabil. 2011;8:59.

31. Filippi M, Rocca MA, Colombo B, Falini A, Codella M, Scotti G, et al. Functional magnetic resonance imaging correlates of fatigue in multiple sclerosis. Neurolmage. 2002;15(3):559-67.

32. Manconi M, Rocca MA, Ferini-Strambi L, Tortorella P, Agosta F, Comi G, et al. Restless legs syndrome is a common finding in multiple sclerosis and correlates with cervical cord damage. Mult Scler. 2008;14(1):86-93.

33. Veauthier C, Gaede G, Radbruch H, Sieb J-P, Wernecke K-D, Paul F. Periodic limb movements during REM sleep in multiple sclerosis: a previously undescribed entity. Neuropsychiatr Dis Treat. 2015:11:2323.

34. Kurtzke JF. Rating neurologic impairment in multiple sclerosis: an expanded disability status scale (EDSS). Neurology. 1983;33:1444-52.

35. Patrick E, Christodoulou C, Krupp L, on behalf of the New York State MS Consortium. Longitudinal correlates of fatigue in multiple sclerosis. Mult Scler. 2008;15(2):258-61.

36. Merkelbach S, Schulz H, Kölmel HW, Gora G, Klingelhöfer J, Dachsel R, et al. Fatigue, sleepiness, and physical activity in patients with multiple sclerosis. J Neurol. 2011;258(1):74-9.

37. Colosimo C, Millefiorini E, Grasso MG, Vinci F, Fiorelli M, Koudriavtseva T, et al. Fatigue in MS is associated with specific clinical features. Acta Neurol Scand. 1995;92(5):353-5.

38. Mills RJ, Young CA. The relationship between fatigue and other clinical features of multiple sclerosis. Mult Scler. 2011;17(5):604-12.

39. Runia TF, Jafari N, Siepman DAM, Hintzen RQ. Fatigue at time of CIS is an independent predictor of a subsequent diagnosis of multiple sclerosis. J Neurol Neurosurg Psychiatry. 2015;86(5):543-6.

40. Marrie RA, Reingold S, Cohen J, Stuve O, Trojano M, Sorensen PS, et al. The incidence and prevalence of psychiatric disorders in multiple sclerosis: a systematic review. Mult Scler. 2015;21(3):305-17.

41. Chiaravalloti ND, DeLuca J. Cognitive impairment in multiple sclerosis. Lancet Neurol. 2008;7(12):1139-51.

42. Rao SM, Leo GJ, Bernardin L, Unverzagt F. Cognitive dysfunction in multiple sclerosis. I. Frequency, patterns, and prediction. Neurology. 1991;41(5):685-91.

43. Urbanek C, Weinges-Evers N, Bellmann-Strobl J, Bock M, Dörr J, Hahn E, et al. Attention Network Test reveals alerting network dysfunction in multiple sclerosis. Mult Scler. 2010;16(1):93-9.

44. DeLuca J, Johnson SK, Natelson BH. Information processing efficiency in chronic fatigue syndrome and multiple sclerosis. Arch Neurol. 1993; 50(3):301-4.

45. Demaree HA, DeLuca J, Gaudino EA, Diamond BJ. Speed of information processing as a key deficit in multiple sclerosis: implications for rehabilitation. J Neurol Neurosurg Psychiatry. 1999;67(5):661-3.

46. McCarthy M, Beaumont JG, Thompson R, Peacock S. Modality-specific aspects of sustained and divided attentional performance in multiple sclerosis. Arch Clin Neuropsychol. 2005;20(6):705-18.

47. Weinges-Evers N, Brandt AU, Bock M, Pfueller CF, Dörr J, Bellmann-Strobl J, et al. Correlation of self-assessed fatique and alertness in multiple sclerosis. Mult Scler. 2010;16(9):1134-40.

48. Guimarães J, Sá MJ. Cognitive dysfunction in multiple sclerosis. Front Neurol. 2012;3:74. doi:10.3389/fneur.2012.00074.

49. Bellmann-Strobl J, Wuerfel J, Aktas O, Dörr J, Wernecke KD, Zipp F, et al. Poor PASAT performance correlates with MRI contrast enhancement in multiple sclerosis. Neurology. 2009;73(20):1624-7.

50. Johnson SK, Lange G, DeLuca J, Korn LR, Natelson B. The effects of fatigue on neuropsychological performance in patients with chronic fatigue syndrome, multiple sclerosis, and depression. Appl Neuropsychol. 1997;4(3): 145-53

51. Kujala P, Portin R, Revonsuo A, Ruutiainen J. Attention related performance in two cognitively different subgroups of patients with multiple sclerosis. J Neurol Neurosurg Psychiatry. 1995:59:77-82.

52. Krupp LB, Elkins LE. Fatigue and declines in cognitive functioning in multiple sclerosis. Neurology. 2000;55(7):934-9.

53. Parmenter BA, Denney DR, Lynch SG. The cognitive performance of patients with multiple sclerosis during periods of high and low fatigue. Mult Scler. 2003;9(2):111-8.
54. Geisler MW, Sliwinski M, Coyle PK, Masur DM, Doscher C, Krupp LB. The effects of amantadine and pemoline on cognitive functioning in multiple sclerosis. Arch Neurol. 1996;53(2):185-8.

55. Schwartz CE, Coulthard-Morris L, Zeng Q. Psychosocial correlates of fatigue in multiple sclerosis. Arch Phys Med Rehabil. 1996;77(2):165-70.

56. Bailey A, Channon S, Beaumont JG. The relationship between subjective fatigue and cognitive fatigue in advanced multiple sclerosis. Mult Scler. 2007;13(1):73-80.

57. Siegert RJ, Abernethy DA. Depression in multiple sclerosis: a review. J Neurol Neurosurg Psychiatry. 2005;76(4):469-75.

58. Arnett PA, Barwick FH, Beeney JE. Depression in multiple sclerosis: review and theoretical proposal. J Int Neuropsychol Soc. 2008;14(5):691-724.

59. Arnett PA, Higginson Cl, Voss WD, Wright B, Bender WI, Wurst JM, et al. Depressed mood in multiple sclerosis: relationship to capacity-demanding memory and attentional functioning. Neuropsychology. 1999;13(3):434-46.

60. Arnett PA, Higginson Cl, Voss WD, Bender WI, Wurst JM, Tippin JM. Depression in multiple sclerosis: relationship to working memory capacity. Neuropsychology. 1999;13(4):546-56.

61. Arnett PA, Higginson $\mathrm{Cl}$, Randolph JJ. Depression in multiple sclerosis: relationship to planning ability. J Int Neuropsychol Soc. 2001;7(6):665-74.

62. Diamond BJ, Johnson SK, Kaufman M, Graves L. Relationships between information processing, depression, fatigue and cognition in multiple sclerosis. Arch Clin Neuropsychol. 2008;23(2):189-99.

63. DeLuca J, Chelune GJ, Tulsky DS, Lengenfelder J, Chiaravalloti ND. Is speed of processing or working memory the primary information processing deficit in multiple sclerosis? J Clin Exp Neuropsychol. 2004;26(4):550-62.

64. Archibald CJ, Fisk JD. Information processing efficiency in patients with multiple sclerosis. J Clin Exp Neuropsychol. 2000;22(5):686-701.

65. Gaudino EA, Chiaravalloti ND, DeLuca J, Diamond BJ. A comparison of memory performance in relapsing-remitting, primary progressive and secondary progressive, multiple sclerosis. Neuropsychiatry Neuropsychol Behav Neurol. 2001;14(1):32-44.

66. Benedict RHB, Cookfair D, Gavett R, Gunther M, Munschauer F, Garg N, et al. Validity of the minimal assessment of cognitive function in multiple sclerosis (MACFIMS). J Int Neuropsychol Soc. 2006;12(4):549-58.

67. Langdon D, Amato M, Boringa J, Brochet B, Foley F, Fredrikson S, et al Recommendations for a Brief International Cognitive Assessment for Multiple Sclerosis (BICAMS). Mult Scler. 2012;18(6):891-8.

68. Kaminska M, Kimoff R, Benedetti A, Robinson A, Bar-Or A, Lapierre Y, et al. Obstructive sleep apnea is associated with fatigue in multiple sclerosis. Mult Scler. 2012;18(8):1159-69.

69. Veauthier C, Gaede G, Radbruch H, Gottschalk S, Wernecke K-D, Paul F. Treatment of sleep disorders may improve fatigue in multiple sclerosis. Clin Neurol Neurosurg. 2013;115(9):1826-30.

70. Cote I, Trojan D, Kaminska M, Cardoso M, Benedetti A, Weiss D, et al. Impact of sleep disorder treatment on fatigue in multiple sclerosis. Mult Scler. 2013 19(4):480-9.

71. Braley TJ, Segal BM, Chervin RD. Hypnotic use and fatigue in multiple sclerosis. Sleep Med. 2015;16(1):131-7.

72. Veauthier C. Hypnotic use and multiple sclerosis related fatigue: a forgotten confounder. Sleep Med. 2015;16(3):319.

73. Baglioni C, Spiegelhalder K, Nissen C, Riemann D. Clinical implications of the causal relationship between insomnia and depression: how individually tailored treatment of sleeping difficulties could prevent the onset of depression. EPMA J. 2011:2(3):287-93.

74. Manconi M, Ferini-Strambi L, Filippi M, Bonanni E, ludice A, Murri L, et al. Multicenter case-control study on restless legs syndrome in multiple sclerosis: the REMS study. Sleep. 2008;31(7):944-52.

75. Li Y, Munger KL, Batool-Anwar S, De Vito K, Ascherio A, Gao X. Association of multiple sclerosis with restless legs syndrome and other sleep disorders in women. Neurology. 2012;78(19):1500-6.

76. Braley TJ, Segal BM, Chervin RD. Sleep-disordered breathing in multiple sclerosis. Neurology. 2012;79(9):929-36.

77. Habukawa M, Uchimura N, Kakuma T, Yamamoto K, Ogi K, Hiejima H, et al. Effect of CPAP treatment on residual depressive symptoms in patients with major depression and coexisting sleep apnea: contribution of daytime sleepiness to residual depressive symptoms. Sleep Med. 2010;11(6):552-7.

78. Schwartz DJ, Karatinos G. For individuals with obstructive sleep apnea, institution of CPAP therapy is associated with an amelioration of symptoms of depression which is sustained long term. J Clin Sleep Med. 2007;3(6):631-5. 
79. Hasselmann H, Bellmann-Strobl J, Ricken R, Oberwahrenbrock T, Rose M,

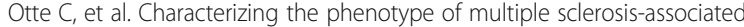
depression in comparison with idiopathic major depression. Mult Scler. 2016;22(11):1476-84

80. Mahajan ST, Patel PB, Marrie RA. Under treatment of overactive bladder symptoms in patients with multiple sclerosis: an ancillary analysis of the NARCOMS patient registry. J Urol. 2010;183(4):1432-7.

81. Buysse DJ, Reynolds CF, Monk TH, Berman SR, Kupfer DJ. The Pittsburgh Sleep Quality Index: a new instrument for psychiatric practice and research. Psychiatry Res. 1989;28(2):193-213.

82. Veauthier C, Paul F. Fatigue in multiple sclerosis: which patient should be referred to a sleep specialist? Mult Scler. 2012;18(2):248-9.

83. Sinnecker T, Mittelstaedt P, Dörr J, Pfueller CF, Harms L, Niendorf T, et al. Multiple sclerosis lesions and irreversible brain tissue damage: a comparative ultrahigh-field strength magnetic resonance imaging study. Arch Neurol. 2012;69(6):739-45

84. Bakshi R, Yeste A, Patel B, Tauhid S, Tummala S, Rahbari R, et al. Serum lipid antibodies are associated with cerebral tissue damage in multiple sclerosis. Neurol Neuroimmunol Neuroinflamm. 2016;3(2):e200.

85. Azevedo CJ, Overton E, Khadka S, Buckley J, Liu S, Sampat M, et al. Early CNS neurodegeneration in radiologically isolated syndrome. Neurol Neuroimmunol Neuroinflamm. 2015;2(3):e102.

86. Zivadinov R, Cerza N, Hagemeier J, Carl E, Badgett D, Ramasamy DP, et al. Humoral response to EBV is associated with cortical atrophy and lesion burden in patients with MS. Neurol Neuroimmunol Neuroinflamm. 2016; 3(1):e190.

87. Pérez-Miralles FC, Sastre-Garriga J, Vidal-Jordana A, Río J, Auger C, Pareto D, et al. Predictive value of early brain atrophy on response in patients treated with interferon $\beta$. Neurol Neuroimmunol Neuroinflamm. 2015;2(4):e132.

88. Paul F. Pathology and MRI: exploring cognitive impairment in MS. Acta Neurol Scand. 2016;134 Suppl 200:24-33.

89. Tartaglia MC, Narayanan S, Francis SJ, Santos AC, De Stefano N, Lapierre Y, et al. The relationship between diffuse axonal damage and fatigue in multiple sclerosis. Arch Neurol. 2004;61(2):201-7.

90. Calabrese M, Rinaldi F, Grossi P, Mattisi I, Bernardi V, Favaretto A, et al. Basal ganglia and frontal/parietal cortical atrophy is associated with fatigue in relapsing-remitting multiple sclerosis. Mult Scler. 2010;16(10):1220-8.

91. Pellicano C, Gallo A, Li X, Ikonomidou VN, Evangelou IE, Ohayon JM, et al. Relationship of cortical atrophy to fatigue in patients with multiple sclerosis. Arch Neurol. 2010;67(4).

92. Yaldizli O, Penner I-K, Frontzek K, Naegelin Y, Amann M, Papadopoulou A, et al. The relationship between total and regional corpus callosum atrophy, cognitive impairment and fatigue in multiple sclerosis patients. Mult Scler. 2014:20(3):356-64.

93. Nygaard GO, Walhovd KB, Sowa P, Chepkoech J-L, Bjornerud A, DueTonnessen $P$, et al. Cortical thickness and surface area relate to specific symptoms in early relapsing-remitting multiple sclerosis. Mult Scler. 2015; 21(4):402-14.

94. Gobbi C, Rocca M, Riccitelli G, Pagani E, Messina R, Preziosa P, et al. Influence of the topography of brain damage on depression and fatigue in patients with multiple sclerosis. Mult Scler. 2014;20(2):192-201.

95. Sepulcre J, Masdeu J, Goni J, Arrondo G, Velez de Mendizabal N, Bejarano B, et al. Fatigue in multiple sclerosis is associated with the disruption of frontal and parietal pathways. Mult Scler. 2009;15(3):337-44.

96. Damasceno A, Damasceno BP, Cendes F. Atrophy of reward-related striatal structures in fatigued MS patients is independent of physical disability. Mult Scler. 2016;22(6):822-9.

97. Roelcke U, Kappos L, Lechner-Scott J, Brunnschweiler H, Huber S, Ammann $W$, et al. Reduced glucose metabolism in the frontal cortex and basal ganglia of multiple sclerosis patients with fatigue: a $18 \mathrm{~F}-$ fluorodeoxyglucose positron emission tomography study. Neurology. 1997;48(6):1566-71.

98. Finke C, Schlichting J, Papazoglou S, Scheel M, Freing A, Soemmer C, et al. Altered basal ganglia functional connectivity in multiple sclerosis patients with fatigue. Mult Scler. 2015;21(7):925-34.

99. Rocca MA, Meani A, Riccitelli GC, Colombo B, Rodegher M, Falini A, et al. Abnormal adaptation over time of motor network recruitment in multiple sclerosis patients with fatigue. Mult Scler. 2016;22(9):1144-53.

100. Dantzer R, O'Connor JC, Freund GG, Johnson RW, Kelley KW. From inflammation to sickness and depression: when the immune system subjugates the brain. Nat Rev Neurosci. 2008;9:46-56.
101. Schedlowski M, Engler H, Grigoleit J-S. Endotoxin-induced experimental systemic inflammation in humans: a model to disentangle immune-to-brain communication. Brain Behav Immun. 2014;35:1-8.

102. Jin S, Kim JG, Park JW, Koch M, Horvath TL, Lee BJ. Hypothalamic TLR2 triggers sickness behavior via a microglia-neuronal axis. Sci Rep. 2016;6: 29424.

103. Hanken K, Eling P, Kastrup A, Klein J, Hildebrandt H. Integrity of hypothalamic fibers and cognitive fatigue in multiple sclerosis. Mult Scler Relat Disord. 2015;4(1):39-46.

104. Giovannoni G, Thompson AJ, Miller DH, Thompson EJ. Fatigue is not associated with raised inflammatory markers in multiple sclerosis. Neurology. 2001;57(4):676-81.

105. Rudick RA, Barna BP. Serum interleukin 2 and soluble interleukin 2 receptor in patients with multiple sclerosis who are experiencing severe fatigue. Arch Neurol. 1990;47(3):254-5.

106. Flachenecker P, Bihler I, Weber F, Gottschalk M, Toyka KV, Rieckmann P. Cytokine mRNA expression in patients with multiple sclerosis and fatigue. Mult Scler. 2004;10(2):165-9.

107. Heesen C, Nawrath L, Reich C, Bauer N, Schulz K-H, Gold SM. Fatigue in multiple sclerosis: an example of cytokine mediated sickness behaviour? J Neurol Neurosurg Psychiatry. 2006;77(1):34-9.

108. Gold SM, Krüger S, Ziegler KJ, Krieger T, Schulz K-H, Otte C, et al. Endocrine and immune substrates of depressive symptoms and fatigue in multiple sclerosis patients with comorbid major depression. J Neurol Neurosurg Psychiatry. 2011;82(7):814-8.

109. Malekzadeh A, Van de Geer-Peeters W, De Groot V, Teunissen CE, Beckerman H, TREFAMS-ACE Study Group. Fatigue in patients with multiple sclerosis: is it related to pro- and anti-inflammatory cytokines? Dis Markers. 2015;2015:758314.

110. Gottschalk M, Kümpfel T, Flachenecker P, Uhr M, Trenkwalder C, Holsboer F, et al. Fatigue and regulation of the hypothalamo-pituitary-adrenal axis in multiple sclerosis. Arch Neurol. 2005;62(2):277.

111. Téllez N, Comabella M, Julià E, Río J, Tintoré M, Brieva L, et al. Fatigue in progressive multiple sclerosis is associated with low levels of dehydroepiandrosterone. Mult Scler. 2006;12(4):487-94.

112. Powell DJH, Moss-Morris R, Liossi C, Schlotz W. Circadian cortisol and fatigue severity in relapsing-remitting multiple sclerosis. Psychoneuroendocrinology. 2015;56:120-31.

113. Jongen PJ, Lehnick D, Koeman J, Frequin S, Heersema D, Kornips B, et al. Fatigue and health-related quality of life in relapsing-remitting multiple sclerosis after 2 years glatiramer acetate treatment are predicted by changes at 6 months: an observational multi-center study. J Neurol. 2014; 261(8):1469-76.

114. Melanson M, Grossberndt A, Klowak M, Leong C, Frost EE, Prout M, et al. Fatigue and cognition in patients with relapsing multiple sclerosis treated with interferon beta. Int J Neurosci. 2010;120(10):631-40.

115. Ziemssen T. Multiple sclerosis beyond EDSS: depression and fatigue. J Neurol Sci. 2009;277:S37-41.

116. Patti F, Amato MP, Trojano M, Bastianello S, Tola MR, Picconi O, et al. Quality of life, depression and fatigue in mildly disabled patients with relapsingremitting multiple sclerosis receiving subcutaneous interferon beta-1a: 3year results from the COGIMUS (COGnitive Impairment in MUltiple Sclerosis) study. Mult Scler. 2011;17(8):991-1001.

117. Kunkel A, Fischer M, Faiss J, Dähne D, Köhler W, Faiss JH. Impact of natalizumab treatment on fatigue, mood, and aspects of cognition in relapsing-remitting multiple sclerosis. Front Neurol. 2015;6:97. doi:10.3389/ fneur.2015.00097. eCollection 2015.

118. Penner I-K, Sivertsdotter EC, Celius EG, Fuchs S, Schreiber K, Berkö S, et al. Improvement in fatigue during natalizumab treatment is linked to improvement in depression and day-time sleepiness. Front Neurol. 2015;6:18.

119. Montalban X, Comi G, O'Connor P, Gold S, de Vera A, Eckert B, et al. Oral fingolimod (FTY720) in relapsing multiple sclerosis: impact on health-related quality of life in a phase II study. Mult Scler. 2011;17(11):1341-50.

120. Calkwood J, Cree B, Crayton H, Kantor D, Steingo B, Barbato L, et al. Impact of a switch to fingolimod versus staying on glatiramer acetate or beta interferons on patient- and physician-reported outcomes in relapsing multiple sclerosis: post hoc analyses of the EPOC trial. BMC Neurol. 2014;14(1):220.

121. Riera R, Porfírio GJ, Torloni MR. Alemtuzumab for multiple sclerosis. Cochrane Database Syst Rev. 2016;4:CD011203.

122. Kappos L, Gold R, Miller DH, MacManus DG, Havrdova E, Limmroth V, et al. Efficacy and safety of oral fumarate in patients with relapsing-remitting 
multiple sclerosis: a multicentre, randomised, double-blind, placebocontrolled phase IIb study. Lancet. 2008;372(9648):1463-72.

123. O'Connor P, Wolinsky JS, Confavreux C, Comi G, Kappos L, Olsson TP, et al. Randomized trial of oral teriflunomide for relapsing multiple sclerosis. $\mathrm{N}$ Engl J Med. 2011;365(14):1293-303.

124. Lerdal A, Bakken LN, Kouwenhoven SE, Pedersen G, Kirkevold M, Finset A, et al. Poststroke fatigue_-a review. J Pain Symptom Manage. 2009;38(6):928-49.

125. Friedman JH, Brown RG, Comella C, Garber CE, Krupp LB, Lou J-S, et al. Fatigue in Parkinson's disease: a review. Mov Disord. 2007;22(3):297-308.

126. Thames AD, Castellon SA, Singer EJ, Nagarajan R, Sarma MK, Smith J, et al. Neuroimaging abnormalities, neurocognitive function, and fatigue in patients with hepatitis C. Neurol Neuroimmunol Neuroinflamm. 2015;2(1):e59-9.

127. Achiron A, Givon U, Magalashvili D, Dolev M, Liraz Zaltzman S, Kalron A, et al. Effect of alfacalcidol on multiple sclerosis-related fatigue: a randomized, double-blind placebo-controlled study. Mult Scler. 2015;21(6): 767-75

128. Moller F, Poettgen J, Broemel F, Neuhaus A, Daumer M, Heesen C. HAGIL (Hamburg Vigil Study): a randomized placebo-controlled double-blind study with modafinil for treatment of fatigue in patients with multiple sclerosis. Mult Scler. 2011;17(8):1002-9.

129. Branas $P$. Treatments for fatigue in multiple sclerosis: a rapid and systematic review. Health Technol Assess. 2000;4(27):1-61. http://www.journalslibrary. nihr.ac.uk/hta/volume-4/issue-27.

130. Shaygannejad V, Janghorbani M, Ashtari F, Zakeri H. Comparison of the effect of aspirin and amantadine for the treatment of fatigue in multiple sclerosis: a randomized, blinded, crossover study. Neurol Res. 2012;34(9):854-8.

131. Ashtari F, Fatehi F, Shaygannejad V, Chitsaz A. Does amantadine have favourable effects on fatigue in Persian patients suffering from multiple sclerosis? Neurol Neurochir Pol. 2009;43(5):428-32.

132. Rossini PM, Pasqualetti P, Pozzilli C, Grasso MG, Millefiorini E, Graceffa A, et al. Fatigue in progressive multiple sclerosis: results of a randomized, doubleblind, placebo-controlled, crossover trial of oral 4-aminopyridine. Mult Scler. 2001;7(6):354-8

133. Weinshenker BG, Penman M, Bass B, Ebers GC, Rice GP. A double-blind, randomized, crossover trial of pemoline in fatigue associated with multiple sclerosis. Neurology. 1992;42(8):1468-71

134. Cohen RA, Fisher M. Amantadine treatment of fatigue associated with multiple sclerosis. Arch Neurol. 1989;46(6):676-80.

135. A randomized controlled trial of amantadine in fatigue associated with multiple sclerosis. The Canadian MS Research Group. Can J Neurol Sci. 1987; 14(3):273-8

136. Asano M, Finlayson ML. Meta-analysis of three different types of fatigue management interventions for people with multiple sclerosis: exercise, education, and medication. Mult Scler Int. 2014;2014:1-12.

137. Lange R, Volkmer M, Heesen C, Liepert J. Modafinil effects in multiple sclerosis patients with fatigue. J Neurol. 2009;256(4):645-50.

138. Krupp LB, Coyle PK, Doscher C, Miller A, Cross AH, Jandorf L, et al. Fatigue therapy in multiple sclerosis: results of a double-blind, randomized, parallel trial of amantadine, pemoline, and placebo. Neurology. 1995;45(11):1956-61.

139. Rosenberg GA, Appenzeller O. Amantadine, fatigue, and multiple sclerosis. Arch Neurol. 1988;45(10):1104-6.

140. Tomassini , Pozzilli C, Onesti E, Pasqualetti P, Marinelli F, Pisani A, et al. Comparison of the effects of acetyl I-carnitine and amantadine for the treatment of fatigue in multiple sclerosis: results of a pilot, randomised, double-blind, crossover trial. J Neurol Sci. 2004;218(1-2):103-8.

141. Peuckmann-Post V, Elsner F, Krumm N, Trottenberg P, Radbruch L. Pharmacological treatments for fatigue associated with palliative care. Cochrane Database Syst Rev. 2010;11:CD006788.

142. Mücke M, Mochamat, Cuhls H, Peuckmann-Post V, Minton O, Stone P, et al. Pharmacological treatments for fatigue associated with palliative care. Cochrane Database Syst Rev. 2015:5:CD006788.

143. Pucci E, Branãs P, D’Amico R, Giuliani G, Solari A, Taus C. Amantadine for fatigue in multiple sclerosis. Cochrane Database Syst Rev. 2007;1:CD002818.

144. Tejani AM, Wasdell M, Spiwak R, Rowell G, Nathwani S. Carnitine for fatigue in multiple sclerosis. Cochrane Database Syst Rev. 2010;2:CD007280.

145. Wingerchuk DM, Benarroch EE, O'Brien PC, Keegan BM, Lucchinetti CF, Noseworthy $\mathrm{JH}$, et al. A randomized controlled crossover trial of aspirin for fatigue in multiple sclerosis. Neurology. 2005;64(7):1267-9.

146. Macdonell R, Nagels G, Laplaud D-A, Pozzilli C, de Jong B, Martins da Silva $A$, et al. Improved patient-reported health impact of multiple sclerosis: The ENABLE study of PR-fampridine. Mult Scler. 2016;22(7):944-54.
147. Applebee A, Goodman AD, Mayadev AS, Bethoux F, Goldman MD, Klingler $M$, et al. Effects of dalfampridine extended-release tablets on 6-minute walk distance in patients with multiple sclerosis: a post hoc analysis of a doubleblind, placebo-controlled trial. Clin Ther. 2015;37(12):2780-7.

148. Allart E, Benoit A, Blanchard-Dauphin A, Tiffreau V, Thevenon A, Zephir H, et al. Sustained-released fampridine in multiple sclerosis: effects on gait parameters, arm function, fatigue, and quality of life. J Neurol. 2015;262(8): 1936-45.

149. Pavsic K, Pelicon K, Ledinek AH, Sega S. Short-term impact of fampridine on motor and cognitive functions, mood and quality of life among multiple sclerosis patients. Clin Neurol Neurosurg. 2015;139:35-40.

150. Grossman P, Kappos L, Gensicke H, D'Souza M, Mohr DC, Penner IK, et al. MS quality of life, depression, and fatigue improve after mindfulness training: a randomized trial. Neurology. 2010;75(13):1141-9.

151. Hebert JR, Corboy JR, Manago MM, Schenkman M. Effects of vestibular rehabilitation on multiple sclerosis-related fatigue and upright postural control: a randomized controlled trial. Phys Ther. 2011;91(8):1166-83.

152. Rietberg MB, Brooks D, Uitdehaag BM, Kwakkel G. Exercise therapy for multiple sclerosis. Cochrane Database Syst Rev. 2005;1:CD003980.

153. Döring A, Pfueller CF, Paul F, Dörr J. Exercise in multiple sclerosis_an integral component of disease management. EPMA J. 2011;3(1):2.

154. Moss-Morris R, McCrone P, Yardley L, van Kessel K, Wills G, Dennison L. A pilot randomised controlled trial of an Internet-based cognitive behavioural therapy self-management programme (MS Invigor8) for multiple sclerosis fatigue. Behav Res Ther. 2012;50(6):415-21.

155. van Kessel K, Moss-Morris R, Willoughby E, Chalder T, Johnson MH, Robinson $\mathrm{E}$. A randomized controlled trial of cognitive behavior therapy for multiple sclerosis fatigue. Psychosom Med. 2008;70(2):205-13.

156. Mohr DC, Hart SL, Goldberg A. Effects of treatment for depression on fatique in multiple sclerosis. Psychosom Med. 2003;65(4):542-7.

157. Thomas PW, Thomas S, Kersten P, Jones R, Slingsby V, Nock A, et al. One year follow-up of a pragmatic multi-centre randomised controlled trial of a group-based fatigue management programme (FACETS) for people with multiple sclerosis. BMC Neurol. 2014;14(1):109.

158. Veauthier C, Gaede G, Radbruch H, Wernecke K-D, Paul F. Sleep disorders reduce health-related quality of life in multiple sclerosis (Nottingham Health Profile Data in Patients with Multiple Sclerosis). Int J Mol Sci. 2015;16(7): 16514-28.

159. Berrigan LI, Fisk JD, Patten SB, Tremlett H, Wolfson C, Warren S, et al. Healthrelated quality of life in multiple sclerosis: direct and indirect effects of comorbidity. Neurology. 2016;86(15):1417-24.

160. Tanigawa T. Obstructive sleep apnea: its prevention and screening may contribute to the prevention of hypertension, diabetes and cardiovascular diseases. EPMA J. 2011;2(1):83-9.

161. Tuleta I, Pabst S, Juergens UR, Nickenig G, Skowasch D. Obstructive sleep apnoea as a risk factor for atherosclerosis -implication for preventive and personalised treatment. EPMA J. 2011;2(1):39-47.

162. Olson L, Cole M, Ambrogetti A. Correlations among Epworth Sleepiness Scale scores, multiple sleep latency tests and psychological symptoms. J Sleep Res. 1998;7(4):248-53.

163. Bastien C. Validation of the Insomnia Severity Index as an outcome measure for insomnia research. Sleep Med. 2001;2(4):297-307.

164. Walters AS, Frauscher B, Allen R, Benes H, Chaudhuri KR, Garcia-Borreguero $D$, et al. Review of diagnostic instruments for the restless legs syndrome/ Willis-Ekbom Disease (RLS/WED): critique and recommendations. J Clin Sleep Med. 2014;10(12):1343-9.

165. Flachenecker $P$, Meissner $H$. Fatigue in multiple sclerosis presenting as acute relapse: subjective and objective assessment. Mult Scler. 2008;14(2):274-7.

166. Allen RP, Picchietti DL, Garcia-Borreguero D, Ondo WG, Walters AS, Winkelman JW, et al. Restless legs syndrome/Willis-Ekbom disease diagnostic criteria: updated International Restless Legs Syndrome Study Group (IRLSSG) consensus criteria-history, rationale, description, and significance. Sleep Med. 2014;15(8):860-73.

167. Wang J, Yin G, Li G, Liang W, Wei Q. Efficacy of physical activity counseling plus sleep restriction therapy on the patients with chronic insomnia. Neuropsychiatr Dis Treat. 2015;11:2771.

168. Lee CS, Lee SD, Kang S-H, Park HY, Yoon I-Y. Comparison of the efficacies of oral iron and pramipexole for the treatment of restless legs syndrome patients with low serum ferritin. Eur J Neurol. 2014;21(2):260-6.

169. Buchfuhrer MJ. Strategies for the treatment of restless legs syndrome. Neurotherapeutics. 2012;9(4):776-90. 
170. Allen R, Chen C, Soaita A, Wohlberg C, Knapp L, Peterson BT, et al. A randomized, double-blind, 6-week, dose-ranging study of pregabalin in patients with restless legs syndrome. Sleep Med. 2010;11(6):512-9.

171. Abetz L, Arbuckle R, Allen RP, Garcia-Borreguero D, Hening W, Walters AS, et al. The reliability, validity and responsiveness of the International Restless Legs Syndrome Study Group rating scale and subscales in a clinical-trial setting. Sleep Med. 2006;7(4):340-9.

172. Kyle SD, Aquino MRJ, Miller CB, Henry AL, Crawford MR, Espie CA, et al. Towards standardisation and improved understanding of sleep restriction therapy for insomnia disorder: a systematic examination of CBT-I trial content. Sleep Med Rev. 2015;23:83-8.

173. Taylor DJ, Schmidt-Nowara W, Jessop CA, Ahearn J. Sleep restriction therapy and hypnotic withdrawal versus sleep hygiene education in hypnotic using patients with insomnia. J Clin Sleep Med. 2010;6(2):169-75.

174. Miller CB, Espie CA, Epstein DR, Friedman L, Morin CM, Pigeon WR, et al. The evidence base of sleep restriction therapy for treating insomnia disorder. Sleep Med Rev. 2014;18(5):415-24.

175. Morin AK, Jarvis Cl, Lynch AM. Therapeutic options for sleep-maintenance and sleep-onset insomnia. Pharmacotherapy. 2007;27(1):89-110.

176. Ancoli-Israel S, Bliwise DL, Nørgaard JP. The effect of nocturia on sleep. Sleep Med Rev. 2011;15(2):91-7.

177. Depressive disorders. In: Diagnostic and Statistical Manual of Mental Disorders. Fifth Edition. American Psychiatric Association; 2013 [cited 2016 May 19]. Available from:http://psychiatryonline.org/doi/abs/10.1176/appi. books.9780890425596.dsm04.

178. World Health Organization. International Statistical Classification of Diseases and Related Health Problems (ICD), vol. 2. 10th ed. Geneva: World Health Organization; 1994.

179. Beck AT, Steer RA. Internal consistencies of the original and revised Beck Depression Inventory. J Clin Psychol. 1984;40(6):1365-7.

180. Patten SB, Burton JM, Fiest KM, Wiebe S, Bulloch AGM, Koch M, et al. Validity of four screening scales for major depression in MS. Mult Scler. 2015;21(8): 1064-71.

181. Minden SL, Feinstein A, Kalb RC, Miller D, Mohr DC, Patten SB, et al. Evidencebased guideline: assessment and management of psychiatric disorders in individuals with MS Report of the Guideline Development Subcommittee of the American Academy of Neurology. Neurology. 2014;82(2):174-81.

182. Golubnitschaja O, Costigliola V, EPMA. General report \& recommendations in predictive, preventive and personalised medicine 2012: white paper of the European Association for Predictive, Preventive and Personalised Medicine. EPMA J. 2012;3(1):14.

183. Pérez LP, González RS, Lázaro EB. Treatment of mood disorders in multiple Sclerosis. Curr Treat Options Neurol. 2015;17(1):323.

184. Koch MW, Glazenborg A, Uyttenboogaart M, Mostert J, De Keyser J. Pharmacologic treatment of depression in multiple sclerosis. Cochrane Database Syst Rev. 2011;2:CD007295.

185. Fiest KM, Walker JR, Bernstein CN, Graff LA, Zarychanski R, Abou-Setta AM, et al, Systematic review and meta-analysis of interventions for depression and anxiety in persons with multiple sclerosis. Mult Scler Relat Disord. 2016;5:12-26.

186. Paul $F$, Veauthier $C$. Fatigue in multiple sclerosis: a diagnostic and therapeutic challenge. Expert Opin Pharmacother. 2012;13(6):791-3.

187. Bove R, White CC, Giovannoni G, Glanz B, Golubchikov V, Hujol J, et al. Evaluating more naturalistic outcome measures: a 1-year smartphone study in multiple sclerosis. Neurol Neuroimmunol Neuroinflamm. 2015;2(6):e162.

188. Mathiowetz VG, Finlayson ML, Matuska KM, Chen HY, Luo P. Randomized controlled trial of an energy conservation course for persons with multiple sclerosis. Mult Scler. 2005;11(5):592-601.

189. Kos D, Duportail M, D'hooghe M, Nagels G, Kerckhofs E. Multidisciplinary fatigue management programme in multiple sclerosis: a randomized clinical trial. Mult Scler. 2007;13(8):996-1003.

190. Hugos C, Copperman L, Fuller B, Yadav V, Lovera J, Bourdette D. Clinical trial of a formal group fatigue program in multiple sclerosis. Mult Scler. 2010 16(6):724-32.

191. Finlayson M, Preissner K, Cho C, Plow M. Randomized trial of a teleconference-delivered fatigue management program for people with multiple sclerosis. Mult Scler. 2011;17(9):1130-40.

\section{Submit your next manuscript to BioMed Central and we will help you at every step:}

- We accept pre-submission inquiries

- Our selector tool helps you to find the most relevant journal

- We provide round the clock customer support

- Convenient online submission

- Thorough peer review

- Inclusion in PubMed and all major indexing services

- Maximum visibility for your research

Submit your manuscript at www.biomedcentral.com/submit

) Biomed Central 